\title{
Laboratory Activities to Introduce Carbohydrates Qualitative Analysis to College Students
}

\author{
Mohamed I. Elzagheid* \\ Department of Chemical and Process Engineering Technology, Jubail Industrial College, Jubail Industrial City, \\ Kingdom of Saudi Arabia \\ *Corresponding author: elzagheid_m@jic.edu.sa
}

\begin{abstract}
This paper presents practical applications of a laboratory inquiry for systematic chemistry learning of carbohydrates. In the laboratory inquiry, students are requested to perform qualitative tests for monosaccharides, disaccharides, and polysaccharides. In addition to that, students are instructed to distinguish specific sugars from non-specific ones. The chemical knowledge and concepts of organic chemistry are actively used to reinforce the previous learning. Such practical activities promote students' readiness for their future career as lab technicians. Our approach is also to link all written laboratory activities with infographics or illustrations to facilitate well understanding of all practical laboratory steps.
\end{abstract}

Keywords: Undergraduate, Graduate, Introductory Chemistry, Laboratory Instructions, Hands-on Learning, Carbohydrates Qualitative Tests

Cite This Article: Mohamed I. Elzagheid, "Laboratory Activities to Introduce Carbohydrates Qualitative Analysis to College Students." World Journal of Chemical Education, vol. 6, no. 2 (2018): 82-86. doi: 10.12691/wjce-6-2-1.

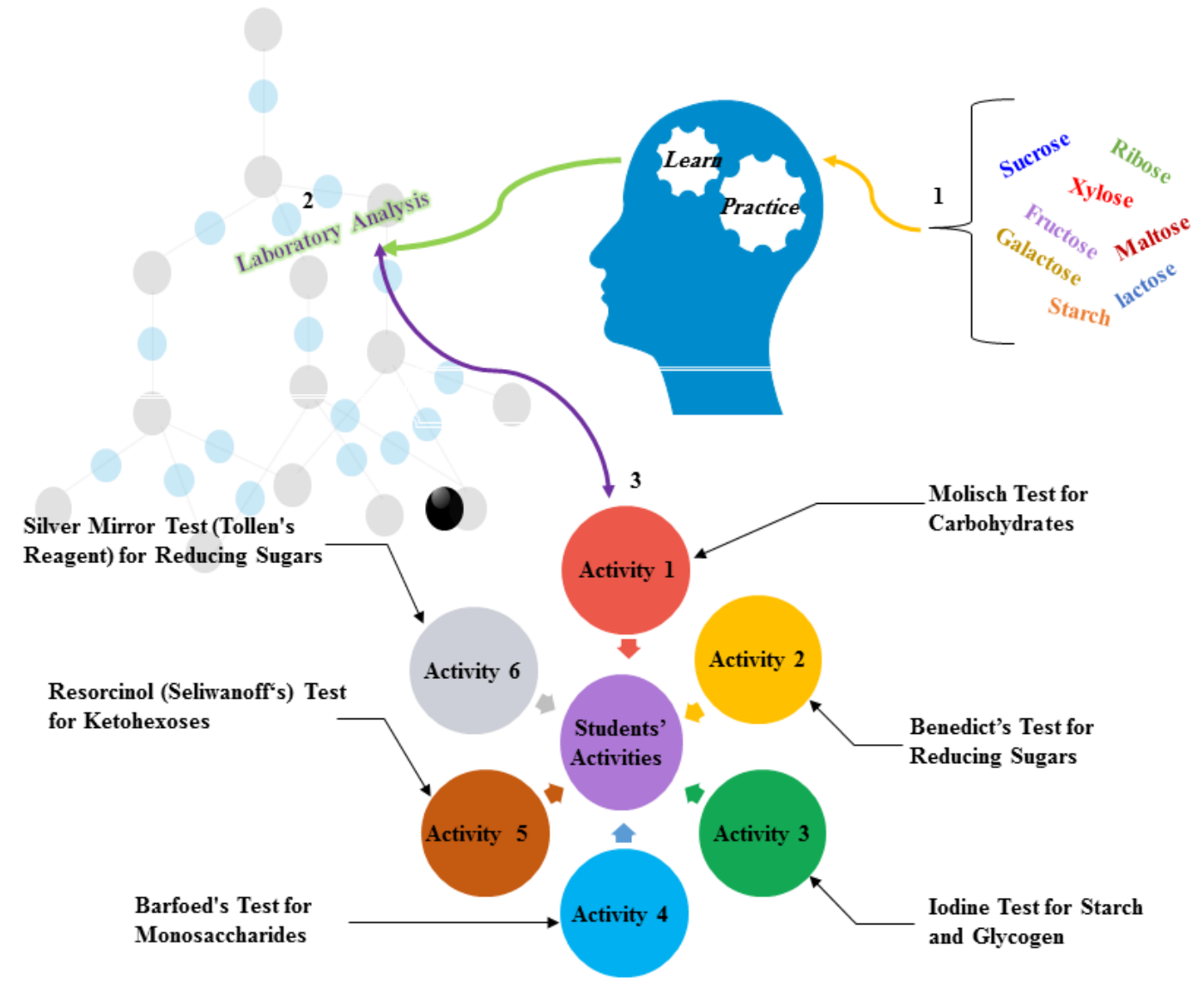

Graphical Abstract: Shows the laboratory analysis of certain carbohydrates by selected qualitative experiments 


\section{Introduction}

Many educational leaders and experts believe that the key to improving student performance lies in improving methodologies of teaching. When academic standards, curriculum and students assessments are aligned to those standards and teachers in charge have the skills to teach at that level student performance will improve. [1-6] Innovative new approaches to deliver laboratory material in undergraduate chemistry laboratory are required. Designing a written or drawn assignment promote better understanding in introductory chemistry courses. [7] This is because good understanding of laboratory instructions in the educational process is associated with excellent learning of chemistry. [8]

Laboratory inquiry, well-organized learning communication, measuring students' meaningful learning, students' participation and applying experimental work in chemistry curricula are all necessary to enhance the learning and establish the teaching experience in more interactive and more effective way in the Laboratory. $[9,10]$ We believe that any practical work should aim to encourage careful recording of laboratory observations, promote simple scientific methods of thought, and develop skills, base training on problem solving. This can be done by different approaches and one approach is to design exercises associated with chemistry laboratory and let students practice them. [11] The weaknesses of any chemistry laboratory program is usually associated with cook booking, lack of experimental design, ignorance of the literature review, and lack of instructor interest. A semester-long laboratory course designed in a format that involves active student participation and critical thinking, lead students to enjoy the lab and become independent players. [12]

A semester-long introduction to macromolecule chemistry laboratory course was designed [13] and run to familiarize students with basic Biomacromolecules experiments. The designed material involves active student participation and guides students to become independent chemists. It teaches them to assume responsibility in a group helps them in decision making and develops their autonomy in writing lab reports.

Hence, we present in this paper laboratory activities for performing carbohydrates' qualitative tests. The current article demonstrates the connection between student academic achievement and teacher classroom practices where students study and conceptualize fundamental concepts of carbohydrates. Therefore, students were divided into small groups (number of groups depends on number of students in each laboratory section). Having three students in each group will facilitate receiving the merged knowledge of theoretical macromolecule chemistry-organic chemistry-biochemistry and have some control over the execution of the total $21 / 2$ hours laboratory work. The allotted time is given to create a scientific thinking and experimental outcome observations subsequently. Diverse students' practical skills encourage students' learning and also increase their interest in science and help in the promotion of understanding of "how science works" to gain more laboratory experience.

\section{Objects}

The aim of this article is to promote acquiring of knowledge by active participation through interactive learning. We also intend to describe the basis of qualitative tests for monosaccharides, disaccharides and polysaccharides in a very simple and straightforward approach.

\section{Laboratory Activities}

Students will do the following activities: Activity 1: Molisch Test for Carbohydrates, Activity 2: Benedict's test for Reducing Sugars, Activity 3: Iodine Test for Starch and Glycogen, Activity 4: Barfoed's Test for Monosaccharides, Activity5: Resorcinol (Seliwanoff's) Test for Ketohexoses, and Activity 6: Silver Mirror Test (Tollen's Reagent) for Reducing Sugars.

To achieve these objects, students perform different laboratory activities, related to carbohydrate analysis and familiarize themselves with methods of preparation of different reagents involved in the analyses.

\section{Experimental Overview and Students' Proposed Tasks}

The instructor provides a complete manual for the experimental procedures as student's handout in line with the students' laboratory discussion. Activities are designed and implemented as part of an industrial chemistry technology course, named as Introduction to Macromolecule Chemistry, for industrial chemistry undergraduates, during the second semester and after the completion of organic chemistry course as a prerequisite. The activities are conducted during the last eighteen academic semesters with approximately 24 students per semester. Students are introduced to the theoretical concepts related to macromolecule chemistry chapter prior to the practical experiments. Students are also distributed into three groups and the experiments are designed to be completed within three laboratory periods $(\approx 2.5 \mathrm{~h})$ as presented in Table 1 .

Table 1. Overview of the students' Performance Tasks

\begin{tabular}{lc}
\hline Task Description & Time (In Minutes) \\
\hline Formation of students' groups (teams) & 10 \\
Distribution of handouts & 10 \\
$\begin{array}{l}\text { Distribution of experimental procedure } \\
\text { tasks among team members }\end{array}$ & 15 \\
Labeling of beakers, preparation of reagent & 75 \\
solutions and performing selected activities & 20 \\
Summarizing results/observations & 20 \\
Cleaning glassware and making place tidy & 150 \\
\hline Total time for all tasks & \\
\hline
\end{tabular}

\section{Handling Chemicals}

Students are given clear instructions on how to handle chemicals involved in the given experiments. [14,15] Instructor explains students' laboratory guidelines and goes through the procedure of the practical activities 
before executing the experiments. Students must always wear protective eye goggles, proper gloves, and laboratory coat. Before performing any given experiment, students must be aware with all hazards associated with it. In addition, students shall always observe good housekeeping principles in the laboratory, wash hands before and after work in the laboratory, and immediately after chemical spills cleanups. Students also reminded to never work alone in any chemical laboratory or leave chemical reaction unattended without arranging appropriate safeguards and be alert and proceed with caution at all times in the laboratory. They also have to notify the instructor immediately of any unsafe conditions.

\section{Activities Procedures}

\section{Activity 1: Molisch Test for Carbohydrates}

Molisch test is a general test used to detect the presence of carbohydrates. If a negative test result is obtained the presence of sugars in the sample is omitted. It is a useful test for identifying any compound which can be dehydrated to furfural or hydroxymethylfurfural in the presence of $\mathrm{H}_{2} \mathrm{SO}_{4}$. Alpha naphthol reacts with the cyclic aldehyde to form purple colored condensation products. [16]

\section{Procedure:}

1. Add 2 drops of Molisch reagent (prepared dissolving $0.1 \mathrm{~g}$ of $\infty$-naphthol in $2 \mathrm{ml}$ of ethanol) to $2 \mathrm{ml}$ of the sugar solution to be tested and mix.

2. Incline the tube, and GENTLY add $2 \mathrm{ml}$ of concentrated sulfuric acid down the side of the test tube.

3. A purple color at the interface between the sugar and acid indicates a positive result as in Figure 1.

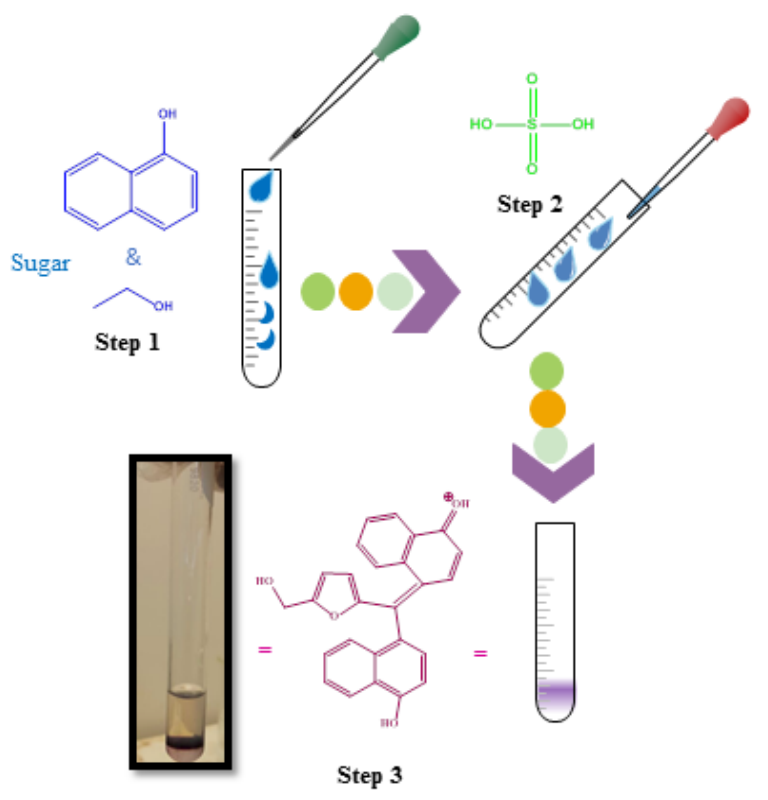

Figure 1. Molisch test for Carbohydrates

\section{Activity 2: Benedict's test for Reducing Sugars}

Benedict's test is a general test for aldehydes and alpha hydroxyl ketones. It can be used to detect the presence of reducing sugars in any given sample.

\section{Procedure:}

1. Add $1 \mathrm{ml}$ of the $2 \%$ sugar solution to be tested to 5 $\mathrm{ml}$ of Benedict's solution (Fresh solution can be prepared by mixing $10 \mathrm{~g}$ sodium carbonate and 17.3 $\mathrm{g}$ monosodium citrate dehydrate in $85 \mathrm{ml}$ water, and while stirring add $10 \mathrm{ml}$ of water containing $1.73 \mathrm{~g}$ copper sulfate then make to a final volume of $100 \mathrm{ml}$ ).

2. Place test tubes in a boiling water bath.

3. Formation of red to brick red precipitate is a positive result as in Figure 2. [17]

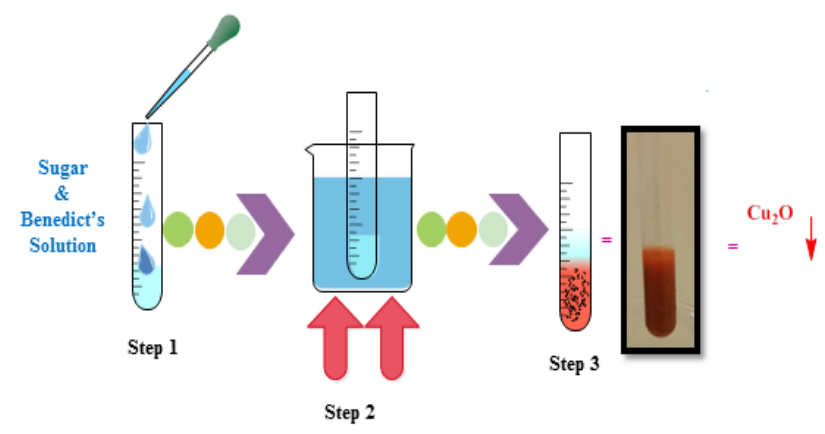

Figure 2. Benedict's test for Reducing Sugars

\section{Activity 3: Iodine Test for Starch}

Iodine reagent (IKI) is used to distinguish starch and glycogen from other monosaccharides and polysaccharides. The reagent yields a blue-black color in the presence of starch (A). Glycogen reacts with the reagent to give a brown-black color. Other polysaccharides and monosaccharides yield yellow-orange color (B). Amylose, in the starch, is responsible for the reaction with iodine. Its helices bind iodine atoms in the solution and produce amylose-iodine complex $\left(\mathrm{I}_{3}{ }^{-}\right.$slides into amylose coil to form a complex that gives a blue-black color) as in Figure 3.

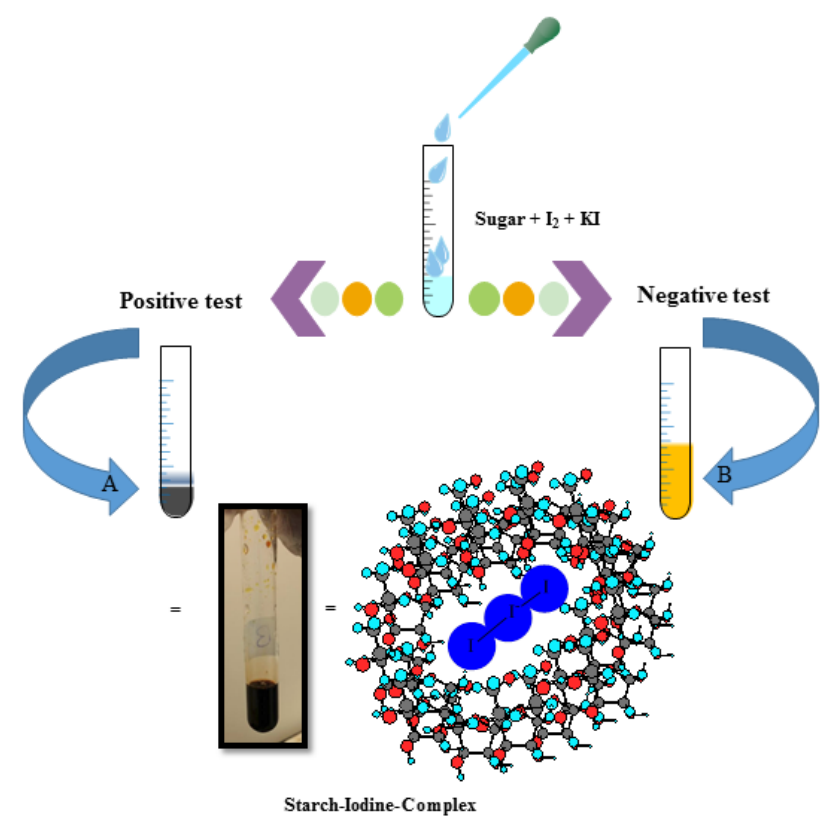

Figure 3. Activity 3: Iodine test for Starch and Glycogen 


\section{Procedure:}

1. Add 2-3 drops of Lugol's iodine solution or (freshly prepared iodine solution, $1 \%$ iodine in $2 \%$ potassium iodide, $1 \mathrm{~g}$ of iodine and $2 \mathrm{~g}$ of $\mathrm{KI}$ dissolved in $100 \mathrm{ml}$ distilled water) to $5 \mathrm{ml}$ of $2 \%$ sugar solution to be tested.

2. Starch gives a blue-black color as shown in Figure 3 (A). Other polysaccharides (except glycogen gives brown-black) and monosaccharides give yellow to brown-yellow color as shown in Figure 3 (B).

\section{Activity 4: Barfoed's Test for Monosaccharides}

Barfoed's reagent is used to detect the presence of reducing monosaccharides in the presence of disaccharides. The reagent, here, uses copper ions to detect reducing sugars in an acidic solution. This test differs from other tests that detect reducing sugars both mono- or disaccharides.

\section{Procedure:}

1. Mix $7 \mathrm{~g}$ of copper acetate monohydrate with $1 \mathrm{ml}$ of glacial acetic acid in distilled water and make the final volume $100 \mathrm{ml}$.

2. Add $1 \mathrm{ml}$ of the $2 \%$ sugar solution to be tested to 3 $\mathrm{ml}$ of Barfoed's reagent.

3. Place test tubes into a boiling water bath and heat for 3-10 minutes. Remove the tubes from the bath and allow cooling.

4. Formation of scanty red precipitate, as in Figure 4, is a positive result for reducing monosaccharides.

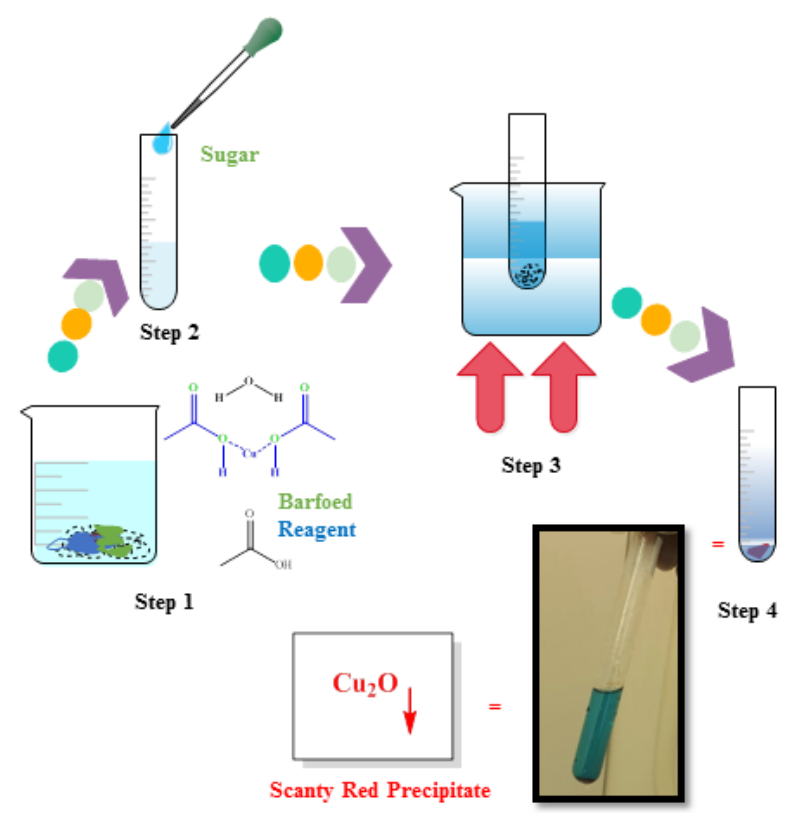

Figure 4. Barfoed's test for Monosaccharides

\section{Activity 5: Resorcinol (Seliwanoff's) Test for Ketohexoses}

Seliwanoff's test used to distinguish ketoses from aldoses. For example, fructose (ketose) will give a cherry red color, while glucose (aldose) will give a negative result with no cherry red, but if heating is continued over 5 minutes, aldoses will sometimes produce a pink color and sucrose (a combination of fructose and glucose) will produce a cherry red color too.

\section{Procedure:}

1. Dissolve $0.1 \mathrm{~g}$ resorcinol in $33 \mathrm{ml}$ concentrated hydrochloric acid $(\mathrm{HCl})$ and make the final volume to $100 \mathrm{ml}$.

2. Add $1 \mathrm{~mL}$ of the $1 \%$ sugar solution to be tested to $10 \mathrm{~mL}$ of the reagent.

3. Heat the solution in a boiling water bath for 5 minutes.

4. A deep cherry or red color within 5 minutes indicates the presence of ketohexoses as in Figure 5. Sucrose gives a positive ketohexose test because of the partial hydrolysis to glucose and fructose.

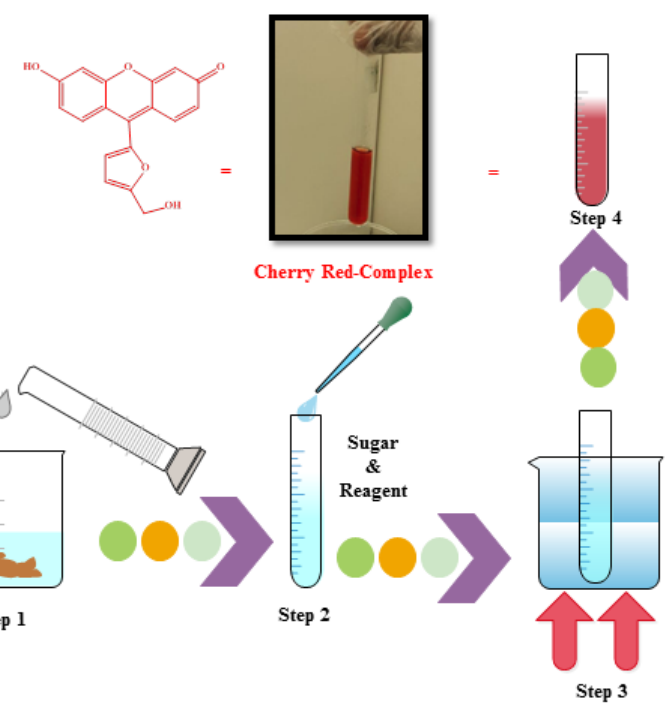

Figure 5. Resorcinol (Seliwanoff's) test for Ketohexose

\section{Activity 6: Silver mirror Test (Tollen's Reagent) for Reducing Sugars}

Tollen's test is used to distinguish between aldehydes and ketones. Tollen's reagent, a solution of silver nitrate and ammonia oxidizes aldehydes but not ketones. The silver ions are reduced to metallic silver which forms a "silver mirror" in the inner surface of the test tube.

\section{Procedure:}

1. Wash the tube with a $10 \%$ solution of sodium hydroxide $(1 \mathrm{~g} \mathrm{NaOH}$ in $10 \mathrm{ml}$ of distilled water).

2. Add $2 \mathrm{ml}$ of a $5 \%(0.5 \mathrm{~g}$ in $10 \mathrm{ml}$ distilled water $)$ silver nitrate solution $\left(\mathrm{AgNO}_{3}\right)$ into the washed tube, then add one drop of the $10 \%$ sodium hydroxide solution.

3. Add one drop of $28 \%$ ammonia solution (add more drops if necessary). Shake constantly. Watch and see just when the silver oxide just dissolves, then add $1 \mathrm{ml}$ of $2 \%$ sugar solution.

4. The formation of a silver mirror in the inner surface of the test tube, as in Figure 6 , is a positive result and an indication of the presence of reducing sugar. 


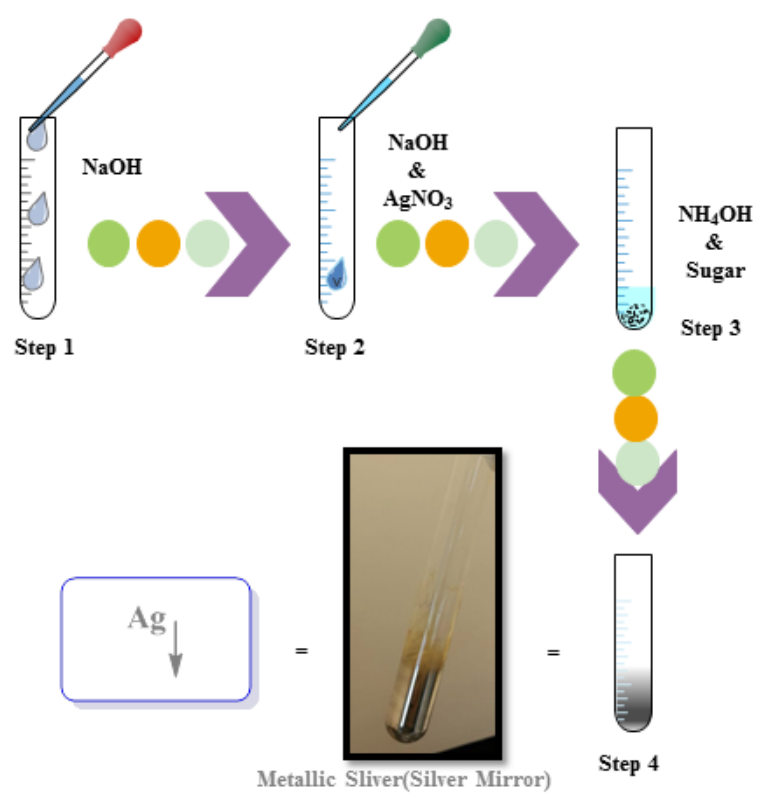

Figure 6. Silver mirror test for reducing sugars

\section{Chemical Hazards}

Protective gloves and goggles must be worn all the time in the laboratory and especially when handling the following chemicals:

- 1-Naphthol: may cause liver, kidney damage, blood abnormalities, and severe eye irritation.

- Sulfuric Acid: concentrated sulfuric acid is extremely corrosive and can cause serious burns when not handled properly.

- Resorcinol: may cause eye and skin irritation.

- Hydrochloric Acid: causes skin corrosion/irritation, and eye damage and eye irritation.

- Ammonia: may explode if heated. Causes severe skin burns.

- Sodium hydroxide: f swallowed, causes severe irritation and chemical burns to the gastrointestinal tract, and can cause permanent eye damage and blindness

\section{Conclusion}

The illustrated practical activities for selected qualitative tests of carbohydrates have proven to be very effectual in performing and practicing laboratory work. The instructional method to explain the student's practical work particularly when there is more than one activity is very beneficial. Hence, we believe that our approach will facilitate better students' understanding and make it more comfortable for them to handle such activities.

\section{Acknowledgments}

Author of this article acknowledges references of this manuscript and thank Dr. Murad Alsawalha and Mr. Mohammed Hanifa for their help in the preparation of the figures.

\section{Statement of Competing Interests}

The author has no competing interests

\section{References}

[1] Pienta, N. J., Cooper, M., Greenbowe, T. J, Chemists Guide to Effective Teaching. Eds. Pearson Education: Upper Saddle River, NJ, 2005, 12-27.

[2] Bruck, L. B., Towns, M, Preparing Students to Benefit from Inquiry-Based Activities in the Chemistry Laboratory: Guidelines and. Suggestions, J. Chem. Educ. 86 (7). 820-822. 2009.

[3] National Research Council. National Science Education Standards, National Academies Press: Washington, DC, 1996, 103-105.

[4] National Research Council. Inquiry and the National Science Education Standards: A Guide for Teaching and Learning, National Academies Press Washington, DC, 2000, 87-88.

[5] Garcia-Martinez, J., Servano-Torregrose, E, Chemistry Education "Best Practices, Opportunities and Trends, Wiley-VCH, 2015, 99-107.

[6] Johnstone, A.H., Al-Shuaili, A, Learning in the Laboratory; Some Thoughts from the Literature. Uni. Chem. Ed, 5 (2). 42-91. 2001.

[7] Oliver-Hoyo, M. T, Designing a Written Assignment to Promote the Use of Critical Thinking Skills in an Introductory Chemistry Course, J. Chem. Educ, 80 (8). 899-903. 2003.

[8] Elliott, M. J., Stewart, K. K. and Lagowski, J. J, The Role of the Laboratory in Chemistry Instruction, J. Chem. Educ, 85 (1). 145-149. 2008.

[9] Logar, A., Peklaj, C., and Savec V. F, Effectiveness of Student Learning during Experimental Work in Primary School, Acta Chim. Slov, 64. 661-67. 2017.

[10] Galloway, K. R., Bretz, S. L, Development of an Assessment Tool To Measure Students' Meaningful Learning in the Undergraduate Chemistry Laboratory, J. Chem. Educ, 92 (7). 1149-1158. 2015.

[11] Reid, N., Shah, I, The role of laboratory work in university chemistry, Chem. Educ. Res. Pract, 8 (2).172-185. 2007.

[12] Murthy, P. P. N., Thompson, M., Hungwe, K, Development of a Semester-Long, Inquiry-Based Laboratory Course in Upper-Level Biochemistry and Molecular Biology, J. Chem. Educ, 91 (11).1909-1917. 2014.

[13] Elzagheid M. I, Introduction to Macromolecule Chemistry, Laboratory Manual, Book Code 561, Jubail Industrial College, Media Resources, Print-shop, KSA, 2009, 12-15.

[14] The National Institute for Occupational Safety and Health (NIOSH). http://www.cdc.gov/niosh/docs/81-123/pdfs/0033.pdf [Accessed Dec. 13, 2016].

[15] Environmental Health \& Safety for the Energy Technologies Area (ETA SAFETY). http://etasafety.lbl.gov/sites/all/files [Accessed Dec. 22, 2017).

[16] Wikimedia: Molisch Test with Glucose by Alex N.B. http://en.wikipedia.org/wiki/File:Molisch_test.png [Accessed Nov.22, 2017].

[17] BioSci: Intro Bios Labs: Benedict's test for Reducing Sugars http://www.biosci.ohiou.edu/introbioslab/Bios170/170_2/benedict. htm [Accessed Nov. 11, 2017]. 